\title{
Community engagement in global health research
}

\section{Dear Editor}

The importance of community engagement in global health research cannot be deemphasized. ${ }^{1-3}$ Despite this, global health researchers still find it difficult to incorporate community engagement in their research, and this is primarily attributed to a lack of explicit guidance. With the increasing need for social justice in health research, ${ }^{4}$ community engagement should be seen as a critical component of research. Many researchers do not have prior thought regarding strategies to properly ensure effective community engagement in the ladder of their research process thinking. In this commentary, we discussed key points that researchers in global health can adopt for successful and effective community engagement for their research.

The community in which research is conducted should not be left out in the actual influence of the findings on them and the kind of health intervention and policy-making that would transpire from such research. This implies community is both key to knowledge creation and how the research affects them. For an effective engagement, the study community or participants needs to be assessed for their activeness in the research process. A passive involvement of the community in the research negates the goal of effective engagement. This emphasizes the need for a balance between an individual's consent to participate in research and the community leader's authorization of its members to get involved in the research. Achieving this balance is proportional to early thinking of community engagement by the researcher. Passive involvement of the identified community in the research can also be prevented by understanding the need and the diversity of the community. This reiterates that global health research should ensure active participation of the community and be community-centered for maximum success.

While we have established the need for early initiation of community engagement, active involvement of the community, and communitycentered approach to global health research, a researcher must also ensure clear, accurate, and unbiased information regarding their research, including the benefits and any potential risk that can result from the research. Investment in maintaining proper and sustained relationships with the community stakeholders is also very important. With this, understanding the community's attitudes, and seeking honest feedback and opinions regarding the proposed research would be easier. This provides an understanding that effective community engagement can build public trust and would make for the implementation of interventions to happen on time. When the trust is earned, it is easier to identify and mobilize local skills and talents to get involved in the proposed research. Naturalizing research in a community by engaging local collaborators and other stakeholders will significantly improve the quality of data collected and its interpretation. This is particularly important for global north researchers that are conducting research in the global south and would facilitate north-south collaborations through the lens of decolonizing global health research via effective knowledge sharing.

Furthermore, the researcher must respect conflicting opinions from the community stakeholders. This can be viewed as perceiving the community to be the local expert of the issues affecting them. The researcher should focus more on negotiation rather than a persuasive approach to the elements of the proposed research. Coercion or any unresolved differing opinions on the proposed research is a threat to effective community engagement. Additionally, to ensure non-cultural conflicting and unbiased decisions by the community regarding proposed research, strategies must be put in place to entertain opposing views and ensure appropriate deliberations. All these emphasize that proposed research would benefit from developing context-specific strategies to seek community consent to participate. Lastly, there should be an opportunity to review, revise and modify community engagement strategies. This implies community engagement strategies are not static but flexible and must be context-specific and ethical.

Community engagement inspires justice in global health research, and scholars, institutions, and other relevant stakeholders should continue to emphasize its relevance in conducting research and developing health interventions.

\section{Declaration of competing interest}

We declared no competing interest.

\section{References}

1. Adebisi YA, Rabe A, Lucero-Prisno III DE. Risk communication and community engagement strategies for COVID-19 in 13 African countries. Health Promot Perspect. 2021;11(2):137-147.

2. Adhikari B, Pell C, Cheah PY. Community engagement and ethical global health research. Global Bioeth. 2019;31(1):1-12.

3. Tindana PO, Singh JA, Tracy CS, et al. Grand challenges in global health: community engagement in research in developing countries. PLoS Med. 2007;4(9):e273. https:// doi.org/10.1371/journal.pmed.0040273.

4. Venkatapuram S. Health research and social justice philosophy. Hastings Cent Rep. 2020;50(6):39-40. https://doi.org/10.1002/hast.1197.

Yusuff Adebayo Adebisi Faculty of Pharmacy, University of Ibadan, Ibadan, Nigeria Global Health Focus, Abuja, Nigeria

Don Eliseo Lucero-Prisno III Department of Global Health and Development, London School of Hygiene and Tropical Medicine, UK Harvard Medical School, Harvard University, Boston, MA, USA

* Corresponding author. E-mail address: adebisiyusuff23@yahoo.com (Y.A. Adebisi). 